\title{
Li Joins JTST Editorial Team
}

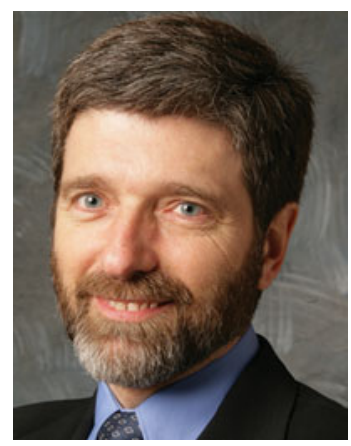

Dr. Christian Moreau

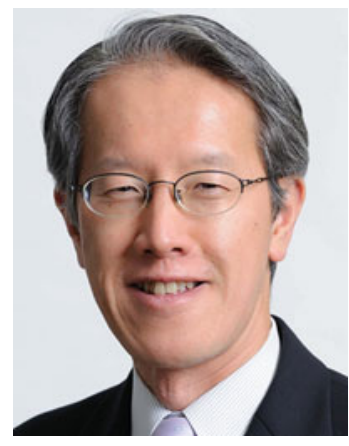

Dr. Seiji Kuroda

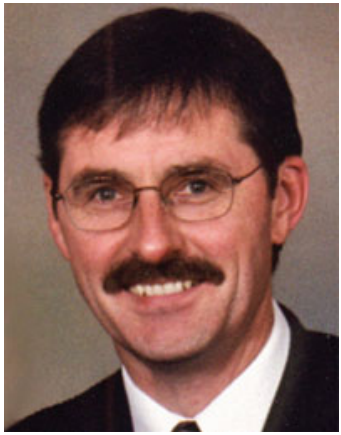

Dr. Basil Marple

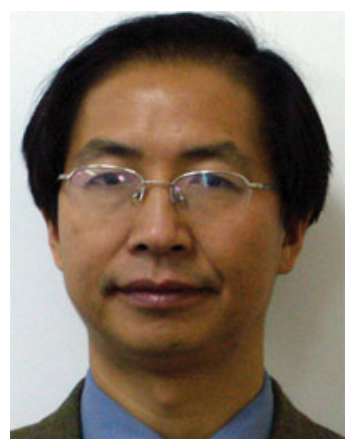

Prof. Chang-Jiu Li

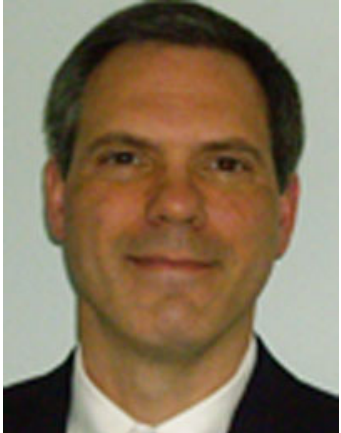

Dr. Kendall Hollis

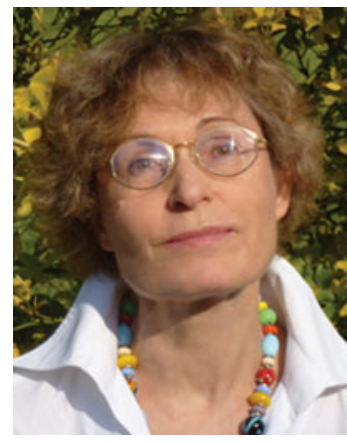

Prof. Armelle Vardelle

Dr. Chang-Jiu Li, Professor, School of Materials Science and Engineering, Xi'an Jiaotong University, has joined the Journal of Thermal Spray Technology (JTST) editorial team as Associate Editor, announced Dr. Christian Moreau, editor-in-chief of JTST, and Dr. Robert C. Tucker, Jr., chair of the JTST Editorial Committee.

Prof. Li received his B.Sc. from the Department of Mechanical Engineering, Xi'an Jiaotong University in 1982. He received his M.S. and Ph.D. in welding engineering from Osaka University in 1986 and 1989, respectively. From 1989 to 1992 , he was a postdoctoral research fellow at the Advanced Materials Processing Institute, Kinki, Japan. During this period, he also worked with Tocalo Company on projects involving HVOF cermet coatings and splat formation in plasma spraying.

In September 1992, he became a lecturer at Xi'an Jiaotong University and was promoted to full professor at the end of 1992 . In 1994, Prof. Li received the Trans-Century Excellent Young Scientists Award from the Ministry of Education of China. He was named a National Natural Science Foundation Distinguished Young Scientist by the Chinese Government in 2007.

Prof. Li leads the thermal spray group at State Key Laboratory for Mechanical Behavior of Materials. Research interests are coating formation mechanisms such as splat formation and lamellar interface bonding, coating microstructure development, and control of wear resistant coatings for high performance coating applications, thermal barrier coatings, and different functional coating applications including fabrication of solid oxide fuel cells by thermal spraying and assembly of dye-sensitized solar cells by thermal spraying.

He has published over 350 academic papers and holds 17 Chinese invention patents. He has been an invited guest editor of special issues of Journal of Thermal Spray Technology for the International Thermal Spray Conference annually from 2007 through 2012 , as well as the 4th Asian Thermal Spray Conference.

Dr. Moreau said, "Prof. Li holds a leading position in the thermal spray research community. His work is internationally recognized and his involvement in events such as ATSC and ITSC as editor of the proceedings and the JTST special issues make him an ideal candidate for this important position. We are fully convinced that Dr. Li will bring a unique contribution to the editorial team to select and publish high quality papers so that the journal continues gaining international visibility and recognition."

Prof. Li joins Dr. Seiji Kuroda and Prof. Armelle Vardelle, who have been JTST associate editors since 2005, and Dr. Kendall Hollis, who has been as associate editor since 2007, as well as Dr. Basil Marple, JTST Lead Editor. 